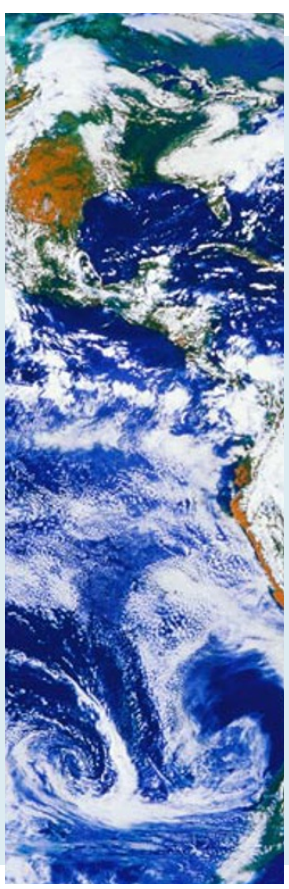

\title{
Planetary boundaries
}

In the latest issue of Nature, a group of leading academics argue that humanity must stay within defined boundaries for a range of essential Earth-system processes to avoid catastrophic environmental change (Nature 461, 472-475; 2009). In proposing the concept of 'planetary boundaries', Johan Rockström of the Stockholm Resilience Centre and co-authors present a new framework for measuring stress to the Earth system and define a safe operating space for human existence on this planet.

Rockström and co-authors suggest preliminary boundaries for the following indicators of environmental change: climate, ocean acidification, stratospheric ozone depletion, freshwater use, biodiversity, the global cycles of nitrogen and phosphorus, and land-use change. They propose that for three of these - the nitrogen cycle, the rate of loss of species and anthropogenic climate change - the maximum acceptable limit has already been transgressed. In addition, they say that humanity is fast approaching the boundaries for freshwater use, for converting forests and other natural ecosystems to cropland and urban areas, and for acidification of the oceans. Crossing even one of these planetary boundaries would risk triggering abrupt or irreversible environmental changes that would be very damaging or even catastrophic for society. Furthermore, if one boundary is transgressed, then there is a more serious risk of breaching the other boundaries.

In this series of Commentaries, seven renowned experts respond to the planetary boundaries concept. Though collectively they represent a broad spectrum of interests across Earth and environmental sciences, each author brings specific expertise to evaluating one aspect of the proposed framework. They ask whether we can currently define, even roughly, the acceptable upper bounds for indicators of environmental degradation, and whether doing so would ultimately help or hinder efforts to protect the planet.

\section{Thresholds risk prolonged degradation}

\author{
WILLIAM H. SCHLESINGER
}

\section{For nitrogen deposition as for other pollution, waiting until we approach the limits of environmental degradation merely allows us to continue our bad habits until it's too late to change them.}

$\mathrm{T}$ hresholds are comforting for decisionmakers. There is no controversy when a high-jumper makes the bar, in contrast to a figure-skater who wins based on form and execution. When the skater doesn't make the grade, there is endless debate about whether the judges were too harsh and what revisions are needed in scoring procedures.

In personal health, as long as we are alive we can be pretty sure we haven't crossed a threshold of dire consequence. But in many cases, identifying and waiting for thresholds also allows misbehaviour that might be better nipped in the bud. Humans don't die of the first cigarette they inhale, but the slow cumulative effects of smoking can hasten the journey towards one's ultimate personal threshold.

Ecologists believe there are numerous thresholds in nature (Nature 413, 591-596; 2001). As we see anthropogenic changes in the Earth system, we need to decide whether we want to allow human activities to disrupt Earth's life-support processes, or whether to begin now to sustain something that is pleasant and potentially more healthful for humans and the other species that share this planet with us. Ongoing changes in global chemistry should alarm us about threats to the persistence of life on Earth, whether or not we cross a catastrophic threshold anytime soon.

Rockström et al. (Nature 461, 472-475; 2009) guess that an acceptable human impact on the global nitrogen cycle should not exceed 25 per cent of the current anthropogenic transfer of nitrogen from the atmosphere to the land surface. This threshold for nitrogen seems arbitrary and might just as easily have been set at 10 per cent or 50 per cent. Since nitrogen can also be denitrified by soil bacteria and ecosystem remediation is theoretically possible, greater human impacts might potentially be tolerated with proper management (Proc. Natl Acad. Sci. USA 106, 203-208; 2009).

But is a threshold really a good idea at all? In areas of excess nitrogen deposition from the atmosphere - for example, in pastures in Great Britain - species decline linearly as a function of increasing nitrogen inputs to the land (Science 303, 1876 -1879; 2004). Some experimental studies with nitrogen fertilizer show a greater loss of species at low levels of excess nitrogen deposition, with diminishing incremental effects thereafter (Nature 451, 712-715; 2008). Waiting to cross the threshold allows much needless environmental degradation.

Rockström et al. set a lenient limit for acceptable human perturbation of the global phosphorus cycle, suggesting it should not exceed ten times the background weathering of phosphorus. But if we cross a threshold for phosphorus that leads to deep oceanic anoxia, we risk a truly dire situation. And lower levels of phosphorus input have well-documented effects on fresh water, which led regulators to set limits on the phosphorus content of detergents nearly 40 years ago.

Moreover, the background value for phosphorus is difficult to estimate. Rivers now carry an estimated $22 \times 10^{12}$ grams of phosphorus per year $\left(\mathrm{gP} \mathrm{yr}^{-1}\right)$ to the sea, but an unknown fraction of that is derived from human activities (Treatise on Geochemistry Vol. 8, 585-643; Elsevier, 2005). Not all phosphorus in rivers is reactive; most is bound to iron and aluminium minerals and is rapidly deposited in marine sediments. The current human contribution to reactive phosphorus in river waters (about 


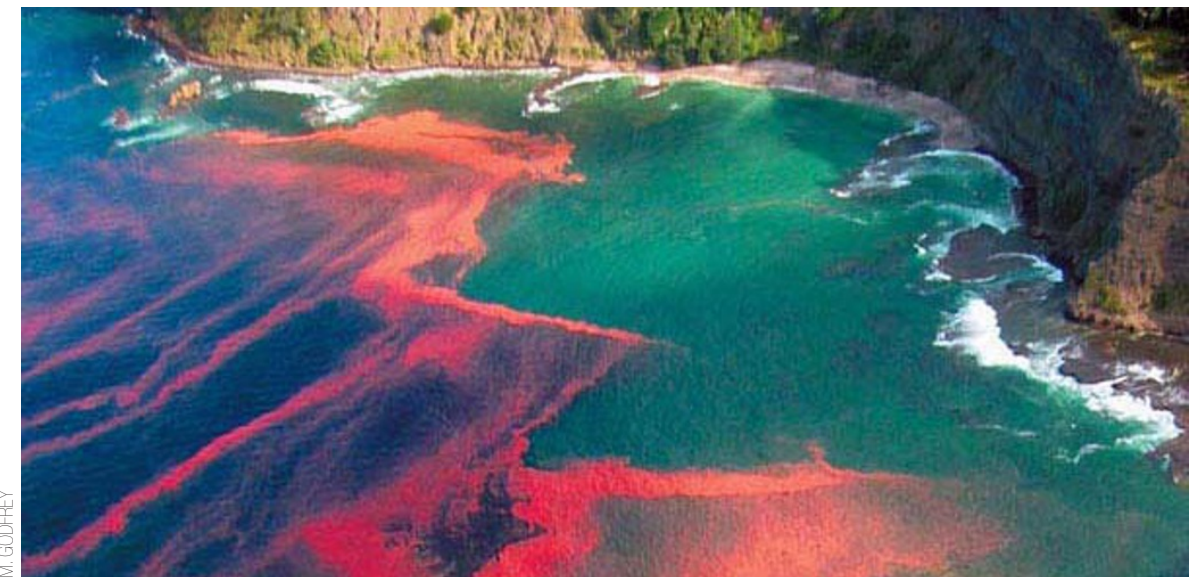

$1 \times 10^{12} \mathrm{gP} \mathrm{yr}^{-1}$; Amer. J. Sci. 282, 401- 450; 1982 ) is probably equivalent to the natural background flux, doubling the total reactive phosphorus load and causing difficulties in coastal waters. The total background flux is probably greater than $11 \times 10^{12} \mathrm{gP} \mathrm{yr}^{-1}$, so the suggested tolerable boundary for the human impact would exceed $110 \times 10^{12} \mathrm{gP}$ $\mathrm{yr}^{-1}$, enough to deplete known phosphorus reserves in less than 200 years and certainly not sustainable.

Unfortunately, policymakers face difficult decisions, and management based on thresholds, although attractive in its simplicity, allows pernicious, slow and diffuse degradation to persist nearly indefinitely. Through the Holocene, atmospheric $\mathrm{CO}_{2}$ was nearly constant; nature mitigated the effects of humans. The human impact on the carbon cycle now exceeds the natural buffering capacity of the Earth system, leading to cumulative changes in the environment for life in every corner of the planet. When these changes are more rapid than evolution, extinctions mount and the ability of the planet to support life is diminished (Nature 427, 145-148; 2004). Setting boundaries is fine, but waiting to act until we approach these limits merely allows us to continue with our bad habits until it's too late to change them.

Published online: 23 September 2009

doi:10.1038/climate.2009.93

William H. Schlesinger is President of the Cary Institute of Ecosystem Studies in Millbrook, New York.

e-mail: schlesingerw@caryinstitute.org

\section{Keep off the grass}

\section{STEVE BASS}

\section{Humanity must learn to live within a stable Holocene environment, but the boundary limit for land use depends on more than the amount of surface covered.}

$\mathrm{J}$ ohan Rockström and colleagues' description of planetary boundaries (Nature 461, 472-475; 2009) is a sound idea. We need to know how to live within the unusually stable conditions of our present Holocene period and not do anything that causes irreversible environmental change.

Planetary boundaries build on a long and respectable tradition of research and thinking on ecological limits, such as the 'limits to growth' thesis of 1972, as well as more recent developments, such as the idea of the ecological footprint and the Millennium Ecosystem Assessment - though Rockström and colleagues would have done well to acknowledge these foundations.

Their paper has profound implications for future governance systems, offering some of the 'wiring' needed to link governance of national and global economies with governance of the environment and natural resources. The planetary boundaries concept should enable policymakers to understand

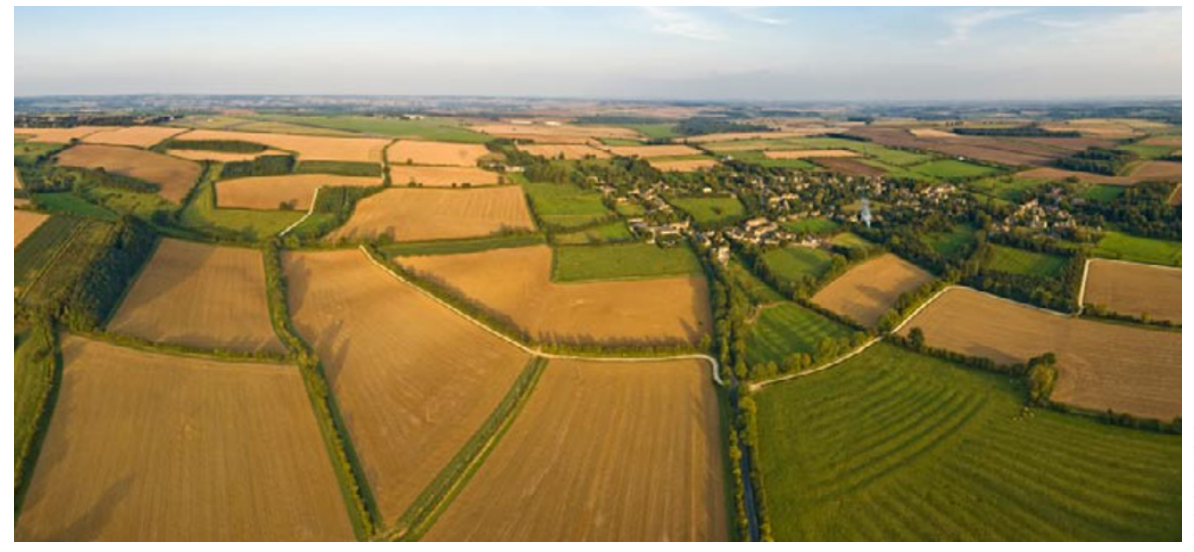

more clearly that, like human rights and representative government, environmental change knows no borders.

That said, there is much work to be done before the concept can be used practically - before it can be 'operationalized'. What policymakers need is a clear instruction that says something to the effect of 'keep off the grass'. What the planetary boundaries paper provides is closer to an index of lawn carrying capacity expressed in terms of soil engineering and grass regeneration.

One of the boundaries described is landuse change. The authors say there needs to be a limit on the amount of the world's land surface that is converted for farming or industry. They suggest that no more 